\title{
Clássicos da literatura infantil: implicações da indústria cultural
}

\author{
Luana Graziela da Cunha Campos ${ }^{1}$ \\ Maria Terezinha Bellanda Galuch² \\ Jéssica Maquiaveli ${ }^{3}$
}

\section{Resumo}

O desenvolvimento de leitor/escritor relaciona-se com as experiências proporcionadas pelos textos a que tem acesso em diferentes situações de mediação. Neste trabalho, objetiva-se refletir sobre a literatura infantil no contexto escolar, destacando-se a implicação da indústria cultural na produção de obras voltadas para a infância. A literatura para crianças, cuja gênese encontra-se em Charles Perrault, é perpassada pela lógica da indústria cultural, mediante a qual a arte se reduz à mercadoria. Nesse sentido, defendem-se práticas pedagógicas com clássicos da literatura infantil em sua forma original, já que novas versões, inseridas no sistema da indústria cultural, podem perder a riqueza dos elementos descritivos e o seu próprio conteúdo, inviabilizando experiências formativas.

Palavras-chave: Teoria Crítica da Sociedade; Histórias Infantis; Conhecimento da Tradição; Experiência; Formação.

\section{Classics of children's literature: implications of the cultural}

\section{Abstract}

The development of reader/writer is related to the experiences provided by the texts they have access to in different mediation situations. In this work, the objective is to reflect on children's literature in the school context, highlighting the implication of the cultural industry in the production of works aimed at children.Literature for children, whose genesis is found in Charles Perrault, is permeated by the logic of the cultural industry, through which art is reduced to merchandise. In this sense, pedagogical practices are defended with classics of children's literature in their original form, since new versions, inserted in the cultural industry system, may lose the richness of descriptive elements and their own content, making training experiences unfeasible.

Keywords: Critical Theory of Society; Children's Stories; Knowledge of Tradition; Experience; Formation.

\section{Considerações iniciais}

No processo de formação dos indivíduos, principalmente na infância, a literatura pode exercer um papel importante no desenvolvimento de funções como a memória, a atenção, a criatividade e a imaginação. Ouvir histórias contribui para a constituição do leitor, e ser leitor possibilita o acesso a um caminho que leva à compreensão e à conscientização sobre o mundo (ABROMOVICH, 1997). A formação do leitor relaciona-se com a vivência social e pode possibilitar

\footnotetext{
${ }^{1}$ Universidade Estadual de Maringá, Maringá, luanagraziela97@outlook.com.

2 Universidade Estadual de Maringá, Maringá, mtbgaluch@uem.br.

${ }^{3}$ Universidade Estadual de Maringá, Maringá, jessicamaquiavel@hotmail.com.
} 
uma melhor participação na sociedade, visto que a escrita faz parte desse universo. Apesar de a formação do leitor não se limitar ao âmbito da vida social, é uma forma de ampliar o conhecimento sobre costumes, sobre valores, bem como sobre a própria história das gerações anteriores, como pontua Abramovich (1997), ou seja, uma forma de se apropriar da cultura que forma os indivíduos e por meio da qual eles podem se expressar.

Se as gerações precedentes têm muito a nos dizer, o passado há que ser revisitado. Adorno (1970) fala da necessidade de elaborar o passado de forma que ele não seja esquecido, mas compreendido como história e seja apresentado como contraponto à realidade atual, tanto como germe do presente, como uma possibilidade de o presente ser outro. Todavia, na sociedade industrial desenvolvida nega-se às pessoas a leitura de fatos históricos fundamentais para o desenvolvimento da sensibilidade. Sobre o fato de a história não ser elaborada, mas apagada, Adorno (1970, p.33) evidencia que "a memória, o tempo e a lembrança são liquidados pela própria sociedade burguesa em seu desenvolvimento".

Na educação escolar, a literatura infantil abre possibilidades para o trabalho docente que busca uma experiência formativa, na perspectiva defendida por Adorno (1996). Essa perspectiva de formação motivou-nos a analisar a história Chapeuzinho Vermelho, em duas de suas versões, sendo uma atual e uma que se aproxima mais à original, com o intuito de compreender aspectos da indústria cultural que acabam implicando práticas pedagógicas com clássicos da literatura infantil. Nesse sentido, neste artigo, refletimos inicialmente sobre a concepção de infância em seu movimento histórico, amparando-nos em obras de Philippe Ariès. Feito isso, buscamos elementos que nos permitam compreender a implicação da indústria cultural na prática escolar com a literatura infantil, fundamentando-nos na Teoria Crítica da Sociedade.

\section{Concepção de infância: breve histórico}

Conforme Ariès (1981), aproximadamente até o século XIII, a infância não era retratada em obras de arte; as crianças eram representadas sob a forma de adultos pequenos. As primeiras representações de crianças com características diferentes das dos adultos ocorrem no contexto em que o ideário do cristianismo estava se fortalecendo e modificando a forma de descrever as pessoas e, sobretudo, as crianças que eram representadas pelo menino Jesus ou pela Nossa Senhora. 
Naquele período, as condições de vida faziam com que grande número de crianças morresse ao nascer, diz Ariès (1981). Isso tornava a mortalidade infantil um fato previsível e motivo para se recomendar aos pais que não se apegassem às crianças, ou seja, a incerteza sobre a sobrevivência dos que nasciam levava os pais a considerarem natural a morte de seus filhos com pouca idade.

Mesmo diante da tradição cultural que recomendava o desapego pela criança, bem como as condições desfavoráveis para a sobrevivência dela, algumas pessoas demonstravam afetividade e se entristeciam com a morte de crianças. Esse fato é comentado por Ariés (1981), que se respalda em registros em túmulos, antes do século XVIII, nos quais eram representadas crianças mortas e vivas, como forma de demonstrar os sentimentos e o respeito pela infância. Tais representações indicam mudanças em relação aos sentimentos dos adultos pelas crianças e ao próprio conceito de infância. No século XVII, torna-se recorrente a representação de crianças sozinhas, bem como retratos de crianças encomendados por familiares.

Aos poucos, o conceito de infância foi se delineando e os discursos que negavam essa etapa da vida e que consideravam as crianças desprovidas de voz e de sentimentos vão perdendo a sua legitimidade. Exemplos disso podem ser encontrados na Teoria Malthusiana ${ }^{4}$, que no século XVIII disseminava métodos contraceptivos para o controle da natalidade, recomendava a vacinação das crianças e os cuidados com a higiene infantil (ARIÈS,1981).

O conceito de infância mais humanizada trouxe mudanças em vários setores da sociedade. Na arte, por meio da representação dos corpos nus; nas roupas, que a partir do século XVII passaram a ser produzidas para as crianças da nobreza, conforme a idade delas; nos cuidados com o corpo e na preocupação com a educação. Acerca da educação, Ariès (1981) assinala que a recomendada às crianças tinha um cunho moralizador, para moldar o caráter e a razão dos sujeitos ainda na infância. Nessa perspectiva, surgem as literaturas pedagógicas destinadas ao público infantil.

\footnotetext{
${ }^{4}$ Diante das condições socioeconômicos da Inglaterra, que foram agravadas no pós-Revolução Industrial, Thomas Robert Malthus elaborou a Teoria Malthusiana, em 1798, que incidia acerca do crescimento demográfico. Malthus afirmava que desastres naturais como guerras e epidemias auxiliariam no crescimento demográfico; caso isso não ocorresse, a população dobraria a cada 25 anos, contudo isso não era proporcional à produção de alimentos. Por isso, definiu-se que a população cresceria em progressão geométrica e os alimentos em progressão aritmética (COSTA et al. 2015).
} 


\section{A literatura infantil}

O conceito de infância trouxe várias discussões acerca das crianças, sobretudo acerca da sua saúde, do seu bem-estar e de como ensiná-las. O pensamento direcionado às crianças contribuiu para o desenvolvimento de uma literatura para esse público. Segundo Coelho (1985), essa literatura advém de histórias que eram contadas oralmente de geração em geração; a partir de tais relatos orientais surgiram os relatos medievais arcaicos, que foram se fortalecendo e disseminando-se como narrativas folclóricas, como literatura folclórica ou ainda como literatura infantil. Conforme Benjamin (1987), essas histórias eram aquelas compartilhadas por meio da narração e poderiam ocorrer em rodas de conversas, nas interações durante o processo de produção artesanal ou em viagens, ou seja, na vida comunitária.

Ainda conforme Coelho (1985), na Idade Média, as narrativas voltadas às crianças tinham um formato diferente da atual literatura infantil, até porque o contexto social era outro. Desse modo, a autora indica dois segmentos diferentes de literatura narrativa: a popular e a culta. A primeira refere-se à contação oral com origem em histórias antigas pautadas em fontes orientais e gregas. A narrativa culta é repleta de idealismo e de um mundo de magia e de maravilhas, tendo por objetivo disseminar valores e comportamentos éticos e sociais (COELHO, 1985). Em outras palavras, eram histórias carregadas de fundo moral e ideológico com a intenção de constituir um pensamento comum entre os leitores. Para isso, era recorrente o uso de fantasia e de violência como elementos coercitivos. Esse aspecto nos remete à visão de Benjamin (1987) de que as histórias narradas eram usadas para aconselhar, ou seja, possuíam um ensinamento implícito como uma de suas características elementares.

Coelho (1985) afirma que o compartilhamento oral de histórias denominadas de literatura popular teve início entre os séculos IX e X, principalmente na Europa. Essas histórias com conteúdos violentos e agressivos foram, aos poucos, adequando-se às necessidades do seu contexto social e, por isso, foram sofrendo modificações, tanto na sua forma, como no seu conteúdo. Da cultura oral, passam-se ao registro; perdem o teor violento da antiga forma, permanecendo, todavia, o conteúdo moralizante, agora adaptado à "sensibilidade" moderna, como destaca Benjamin (2002). Atualmente, são conhecidas como literatura folclórica ou literatura infantil. 
Compreendendo-se a função educativa da literatura infantil, bem como a sua capacidade de promover momentos prazerosos, de despertar emoções e de transmitir tradições de geração para geração, Coelho (1985) acrescenta que esse tipo de literatura proporciona o conhecimento do passado, de modo que o presente possa ser mais humanizado, destacando que o desenvolvimento tecnológico e dos meios de comunicação facilitaram o acesso às histórias infantis.

Segundo Benjamin (1987), é justamente pela invenção da imprensa que as histórias foram materializadas sob a forma escrita e disseminadas em larga escala. Nessa perspectiva, é possível perceber que também a literatura infantil se transforma em mercadoria, com a participação direta da indústria cultural. Giovinazzo Júnior (2004), ao explicar esse processo, apresenta aspectos positivos e negativos no âmbito da indústria cultural, ou seja, ao mesmo tempo em que a indústria cultural amplia o acesso das pessoas aos livros, permite que o conteúdo deles se adeque às necessidades do capital. Isso nos leva a, na próxima seção, focar na relação da indústria cultural com a produção da literatura infantil.

\section{Literatura infantil e indústria cultural}

O movimento iluminista acompanhou a ascensão da sociedade burguesa, sendo, inclusive, impulsionado pelas novas condições objetivas. De acordo com Oliveira (2019), o Iluminismo pode ser caracterizado como um movimento de intelectuais que se manifesta na Europa durante o século XVIII, cujo resultado são diversas transformações nas esferas política, econômica e social. Os principais ideais elencados por seus precursores foram a liberdade econômica e a liberdade política, com foco no fortalecimento da ciência e da razão. O avanço da ciência e da razão possibilitaram o avanço da riqueza social, todavia o lucro como elemento fundante da sociedade capitalista impossibilita a aplicação da própria ciência e da razão em benefício de todos. Destaca-se, ainda, que a tecnologia possibilitou elevar a produção de mercadorias, mas se põe, também, como um mecanismo para o controle em diferentes âmbitos sociais.

De acordo com Adorno e Horkheimer (1985), o esclarecimento buscava, pelo conhecimento, libertar os homens do mito e do medo, contudo o cenário social que se diz 
esclarecido não abandonou a calamidade, ou seja, o projeto de liberdade converteu-se em forma de exercício poder. A ciência serve aos fins da economia burguesa tanto na fábrica quanto fora dela.

Sobre as formas de controle exercidos pela sociedade capitalista, Marcuse (1973) explica que há uma racionalidade na lógica irracional que opera o capitalismo, por exemplo, a necessidade de tornar os sujeitos individualistas, eficazes e produtivos, propagando o discurso da livre competição, mesmo que ele ocorra sob condições econômicas desiguais. Essa organização social, em vez de impulsionar o desenvolvimento da individualidade, favorece a constituição de capacidades mecanizadas e necessárias ao mercado produtivo, assim a concentração de riquezas se fortalece nas mãos de poucos e a competição passa a ser o marco da vida, fortalecendo cada vez mais a própria organização social que gera a competição.

No cenário de desenvolvimento dos meios de produção, no fim do século XIX, a educação pública foi pensada para ajustar os homens ao capital sem resistência de quaisquer partes. A escola pública foi criada para manter e ao mesmo tempo desenvolver a economia conforme os anseios da sociedade burguesa. Nesses termos, Marx e Engels (2011) evidenciam a criação da escola pública para fins econômicos e não propriamente para o desenvolvimento de indivíduos autônomos e emancipados. Eles alertam que a educação, ao buscar atender aos anseios do capital, tende a preparar com eficiência trabalhadores qualificados e a disseminar a ideologia burguesa. A educação que deveria proporcionar a formação para a autonomia, desde a sua criação, apresenta-se como um mecanismo que atende a interesses econômicos.

Nesses termos, o acesso democrático aos bens culturais não ocorreu nessa sociedade. A liberdade é limitada pela dominação à qual a vida humana é submetida. A indústria cultural legitima a irracionalidade e reproduz a sociedade do sempre-idêntico, deformando os indivíduos, na medida em que, para manter a coesão social, difunde ideias que inviabilizam a liberdade (OLIVEIRA; GALUCH; GIOVINAZZO JÚNIOR, 2019). Na perspectiva desses autores, na sociedade administrada, a educação, se descomprometida com a formação cultural, tende a seguir o capital e moldar os indivíduos conforme os preceitos desse modo de organização social, em vez de buscar a satisfação de interesses humanos. Por isso, de maneira geral, os pensamentos e as ações dos homens pouco destoam daquilo definido pela indústria cultural.

O fortalecimento do capitalismo e a difusão da promessa do progresso resultaram na 
manipulação da cultura. A educação é submetida a práticas pedagógicas que pouco se atém à formação cultural pautada em conteúdos $^{5}$ historicamente constituídos. Mesmo que os conteúdos não sejam o único fator necessário à formação para a emancipação, conforme explica Adorno (1970), o conteúdo ligado à história, ao passado e ao presente é fundamental para um ensino que pretenda trazer autonomia ao pensamento e que busque proporcionar experiências formativas.

A capacidade de fazer experiências, para Adorno (1970), não diz respeito apenas ao acesso aos conteúdos, mas àquilo que eles podem promover em termos de conhecimento de mundo, de transmissão da cultura e do compartilhamento da tradição. Contudo, percebemos que a experiência é prejudicada na sociedade industrial desenvolvida; como evidenciam Adorno e Horkheimer (1985), nada escapa à lógica capitalista e ao controle da indústria cultural, inclusive à educação.

A infância representa para a indústria cultural um potencial mercado para a venda de materiais didáticos e de literatura infantil. Assim, o livro, historicamente reconhecido como fonte de conhecimento, mediante a indústria cultural, torna-se apenas mercadoria para atender a interesses econômicos. Como outra mercadoria qualquer, ele é um negócio com o qual visa-se ao lucro.

Nesses termos, Giovinazzo Júnior (2004) salienta que a mesma ciência e a mesma tecnologia que possibilitaram a ampliação da quantidade dos livros impressos, limitaram o seu conteúdo e a possibilidade de, por meio deles, promover experiências; ao mesmo tempo que as literaturas foram popularizadas, significativas mudanças foram realizadas nos livros de literatura, nos seus conteúdos e nas suas narrativas. Em muitos casos, perderam-se os elementos históricos, aquilo que no livro poderia proporcionar a reflexão, a construção de experiências, que poderia contribuir com o desenvolvimento de indivíduos autônomos, viabilizando ao homem a possibilidade de resistir ao controle e à adaptação à sociedade. Para Adorno (1970), quando a população passa a ter acesso à educação, ela tem o conteúdo manipulado com a participação,

\footnotetext{
${ }^{5}$ Na obra Educação e emancipação, Adorno (1970) reflete sobre a importância dos conteúdos na educação que tem como objetivo a emancipação. Para o autor, o trabalho educacional pautado nos conteúdos é importante, porém somente uma educação conteudista não daria conta de garantir a autonomia. Seria necessário, além dos conteúdos, proporcionar reflexões que desenvolvam a sensibilidade e a humanização.
}

Periódico Horizontes - USF - Itatiba, SP - Brasil - e021066 
também, da indústria cultural. Nesse sentido, entendemos que a literatura infantil passa por processo similar, como demonstra Giovinazzo Júnior (2004), ao pontuar a crescente incapacidade de a literatura infantil concorrer para que as crianças realizem experiências, ou seja, a incapacidade de a literatura infantil proporcionar às crianças a reflexão e a compreensão da realidade, que observem possibilidades de a realidade ser outra. Desvinculada de conteúdo, a literatura limita-se a informar o receptor.

Benjamin (1987) diz que desde o século XIX a falsa cultura ganha espaço, gerando a perda da capacidade de comunicação em todos os âmbitos culturais. Neste sentido, para elucidar a inaptidão ou a incapacidade de narrar, Benjamin (1987) comenta que ela está presente nos mais variados meios de comunicação, do jornal ao rádio. Salienta, ainda, que o controle imposto pela indústria cultural interfere diretamente na capacidade de transmitir experiências de uma pessoa para a outra, perdendo-se a tradição oral, uma vez que nesse cenário as pessoas não têm mais aconselhamentos para compartilhar.

A adesão aos livros de literatura, mesmo destituídos de conteúdo, aproxima-se da ideia de Adorno e Horkheimer (1985) sobre a adesão voluntária às mercadorias. Os autores não falam especificamente sobre os livros de literatura, mas sobre as mercadorias produzidas de modo geral na sociedade capitalista e sobre a necessidade de consumo desenvolvida e manipulada pela indústria cultural. Marcuse, por sua vez, refere-se à incorporação de necessidades pelos indivíduos nos seguintes termos:

[...] as necessidades que efetivamente são oferecidas aos indivíduos por instituições, e que em muitos casos são impostas sobre os indivíduos, acabam se tornando as próprias necessidades e desejos dos indivíduos. Esta aceitação de necessidades sobrepostas leva a uma estrutura de caráter afirmativa. Leva à afirmação e à conformação ao sistema de necessidades estabelecido, sejam a afirmação e a conformação voluntárias ou forçadas (MARCUSE, 2018, p.194).

A reflexão sobre o controle leva-nos a pensar sobre o fato de que nas escolas é difícil encontrarmos literaturas como as de Charles Perrault, as de Hans Christian Andersen, as dos Irmãos Grimm, as de Lewis Carrol e as de Jean de La Fontaine, em versões que não as infiltradas pela redução na descrição dos fatos e do conteúdo e pela ampliação de aspectos que fazem a propaganda, ou seja, na forma tipicamente com fins mercadológicos. Pouco se observam na 
escola análises acerca das escolhas de literatura infantil para compor o planejamento pedagógico, visto que os livros didáticos das escolas públicas são previamente selecionados por programas nacionais como o Programa Nacional do Livro e do Material Didático (PNLD). Tais programas são importantes, pois levam literaturas às escolas, mas também é uma forma de o Estado controlar o que se lê nesses espaços, já que as literaturas são escolhidas pelas escolas conforme as obras disponíveis nos editais do PNLD Literário.

Nossa observação referente ao PNLD Literário não é no sentido de desqualificá-lo ou de desqualificar as obras por ele selecionadas, mas de expressar sua ambiguidade: ao mesmo tempo que é uma possibilidade para a formação, já que amplia o acesso às literaturas, põe-se como limite, porque seleciona previamente esses materiais e porque a própria literatura foi alterada, assumindo contornos mercadológicos.

Nesses termos, observa-se que também a literatura infantil entra no rol das mercadorias a serviço da sociedade para formar indivíduos com determinada subjetividade. Assim, desde a infância, os indivíduos têm a sua individualidade perpassada pelo social. Vale ressaltar que, como explicam Adorno e Horkheimer (1985), não há uma cultura produzida pelas massas, mas uma cultura produzida pela indústria cultural e imposta às massas com a finalidade de massificação, padronização, controle e manipulação das necessidades, do pensamento e da formação.

Assim, a literatura infantil, por vezes, atua como instrumento para a disseminação da ideologia da sociedade industrial desenvolvida, limitando a formação cultural das crianças a esse conteúdo. Portanto, popularizar a literatura não foi uma solução para o acesso aos bens culturais, mas um mecanismo que transforma a literatura infantil em mercadoria e manipula a formação das pessoas. Essa popularização da literatura, segundo Benjamin (1987), é o reflexo da reprodução em larga escala da literatura e esse processo modificou o conteúdo das histórias. Do ponto de vista da experiência, as histórias que se mantiveram mais próximas do conteúdo da oralidade são as que mais têm potencial para a experiência. Isso nos leva a pensar que essas histórias são aquelas em versões mais clássicas, originais, com mais detalhes, com um conteúdo capaz de levar o leitor/ouvinte a reelaborar a experiência narrada.

Nossa reflexão crítica não se refere à popularização da literatura, mas à literatura infantil como mais um tentáculo da indústria cultural e ao esvaziamento dos conteúdos que limitam as possibilidades formativas, pois, assim como pontua Kramer (2000), acreditamos que a formação 
cultural é um dos elementos imprescindíveis para uma sociedade verdadeiramente democrática.

O contato com a produção cultural em forma de literatura, por exemplo, possibilita às crianças o desenvolvimento da consciência crítica. Pela literatura, é possível conhecer o contexto histórico e, tal como as políticas para a infância, discutir sobre valores, "[...] reconhecer as diferenças, combatendo a desigualdade, ao garantir a posse do conhecimento, questão central da distribuição do poder" (KRAMER, 2000, p.9). O conhecimento universal e a compreensão da história conduzem à superação da particularidade; permitem reconhecer que "falar de conhecimento é, pois, falar de cidadania" (KRAMER, 2000, p.9). Conforme Adorno (1970), a cidadania será verdadeira quando os indivíduos se encontrarem emancipados; e é nesse sentido que destacamos a importância da literatura infantil comprometida com a formação para as experiências e para o desenvolvimento da autonomia e da sensibilidade.

Diante das mudanças sociais, buscamos compreender se as histórias atualmente contadas às crianças apresentam características como a linguagem rica em detalhes, a preservação da história e, portanto, se contribuem para a experiência.

\section{Limites e possibilidades da literatura infantil como elemento formativo: o clássico Chapeuzinho Vermelho de Perrault}

Falar sobre de literatura clássica pressupõe pontuar sobre a concepção de clássico adotada para embasar a análise. Para Saviani (2013, p.13),

[...] clássico não se confunde com o tradicional e também não se opõe, necessariamente, ao moderno e muito menos ao atual. O clássico é aquilo que se firmou como fundamental, como essencial [...] que resistiu aos embates do tempo [...] clássico, em verdade, é o que resistiu ao tempo.

Isso evidencia que clássico é aquilo que foi capaz de percorrer o tempo, de perdurar nas sociedades e ainda ser repleto de credibilidade. Outra concepção de clássico é a proposta por Calvino (1993, p.9), para quem "Os clássicos são livros que exercem uma influência particular quando se impõem como inesquecíveis e também quando se ocultam nas dobras da memória, mimetizando-se como inconsciente coletivo ou individual", isto é, o clássico é repleto de 
memória particular e coletiva. Particular, pois cada um que teve contato com a história, guarda a experiência e a memória; coletiva, porque essa experiência e essa memória não são apenas de uma pessoa ou apenas de uma geração. Os clássicos atravessam gerações. Exemplo disso pode ser obtido ao perguntarmos, quer seja para um grupo de crianças, quer seja para um grupo de adultos, se alguém conhece a história da Cinderela. Certamente, teremos respostas afirmativas em ambos os grupos.

Quando nos reportamos a obras literárias destinadas ao público infantil, as histórias que impactaram o início desse tipo de literatura permanecem até nossos dias. Entre as histórias de Charles Perrault, podemos citar Chapeuzinho Vermelho, O Pequeno Polegar, A Bela Adormecida, A Cinderela, $O$ Gato de Botas e tantas outras. É comum que esses títulos tenham feito e ainda façam parte da infância de muitas crianças, inclusive nas práticas escolares. Contudo, o fato de haver muitas versões dessas histórias nos leva a questões acerca das suas peculiaridades. Embora elas tenham se perpetuado, versões recentes sofreram alterações em relação à original, o que não se restringe a aspectos da tradução para diferentes línguas. A tecnologia possibilitou novas ilustrações, novas encadernações, novos formatos e, também, a simplificação, a redução, o corte de detalhes, ou seja, outra forma de narrar e, inclusive, outro conteúdo.

Por que isso ocorre? Na busca de possíveis respostas, analisaremos uma história em uma versão mais próxima à original e uma versão adaptada e divulgada atualmente.

Para a análise, optamos pela versão da obra Um conto de fadas: Chapeuzinho vermelho, história de Charles Perrault (2012), que recontou histórias populares narradas pelos camponeses, reescrevendo-as com princípios educativos e moralizantes, especialmente para o público infantil, de tal sorte que ficaram conhecidas mundialmente. A fonte utilizada é a publicada como parte da coletânea "Contos da Mamãe Gansa". Muitas dessas histórias foram modificadas posteriormente por outros autores, sobretudo pelos irmãos Grimm. Na obra Chapeuzinho Vermelho, os irmãos Grimm acrescentaram, no fim da história, o personagem do lenhador que salva a Chapeuzinho Vermelho e a sua avó, retirando a velhinha da barriga do lobo. A outra versão dessa história escolhida para analisarmos é a de Cristina Marques [2008?], publicada pela Editora Todolivro, sob o título Chapeuzinho Vermelho, como parte da Coleção Clássicos Infantis. Essa versão se assemelha com a versão escrita pelos irmãos Grimm, já que também nela a barriga do lobo é aberta para que a vovó seja salva. 
As histórias registradas por Perrault demonstram a preocupação histórico-social com a educação das crianças do momento em que foram produzidas. O autor fez isso sem que suas obras perdessem a relação com o seu tempo, sem que deixassem de ensinar e de distrair os leitores.

Na obra Chapeuzinho vermelho (PERRAULT, 2012), percebemos a intenção de ser transmitida uma lição de moral e a presença de aspectos pedagógicos explicitados pela forma como o autor, utilizando a fantasia, a criatividade e a afetividade, comunica aos leitores as experiências vividas pela menina no bosque, tal como na passagem a seguir:

Era uma vez uma pequena aldeã, a menina mais bonita que poderia haver. Sua mãe era louca por ela e a avó, mais ainda. Esta boa senhora mandou fazer para a menina um pequeno capuz vermelho. Ele lhe assentava tão bem que por toda parte aonde ia a chamavam de Chapeuzinho Vermelho (PERRAULT, 2012, p.6).

Notam-se elementos que localizam a menina, a mãe e a avó em uma relação afetiva entre três gerações. No trecho em destaque, há, ainda, a descrição da menina e a apresentação do motivo pelo qual ela é chamada de 'Chapeuzinho Vermelho'. Esta narração conduz o leitor à imaginação, permitindo que se pense no belo. Embora com poucas palavras, a forma como a perfeição da peça confeccionada por sua avó é apresentada revela não apenas a beleza do chapéu, mas também a da menina. Aqui, a palavra expressa o conceito. Isso não é constatado na versão escrita por Marques [2008?], que traz a informação sobre o nome da menina sem elementos que ultrapassem a informação em si e provoquem curiosidade, tampouco apresenta aspectos que possam conduzir a outras possibilidades de nomear a menina, já que se limita a dizer: "Era uma vez uma menina conhecida como Chapeuzinho Vermelho" (MARQUES, 2008?, p.3). Também não há pontos que remetem à relação de amor entre a neta, a mãe e a avó, nem há a menção de que se trata de uma menina que reside em uma aldeia.

Ao se referir ao local em que a avó reside, Perrault descreve: "Mora depois daquele moinho lá longe, bem longe, na primeira casa da aldeia" (PERRAULT, 2012, p.7). Assim, é possível a criança dimensionar a distância, já que o narrador deixa claro que sua casa não é somente depois do moinho. Já na versão de Marques [2008?], em uma passagem que faz referência a distância entre a casa da Chapeuzinho e de sua avó, podemos ler: "Um dia, sua mãe pediu que ela levasse uma 
cesta de doces para sua vovó, que morava do outro lado do bosque" (MARQUES, 2008?, p.3).

Outro fato que nos chama a atenção é que, em Perrault (2012), há detalhes que explicitam o cuidado, o zelo pelo outro. Quando a mãe pede que Chapeuzinho leve o bolinho e o pote de manteiga para a sua avó, ela demonstra preocupação com a saúde dela, dizendo: “Vá visitar sua avó para ver como ela está passando, pois me disseram que está doente" (PERRAULT, 2012, p.6). Na versão de Marques [2008?], a solicitação para a menina levar os doces não decorre de uma preocupação com a saúde da avó, como podemos ler: "sua mãe pediu que ela levasse uma cesta de doces para sua vovó" (MARQUES, 2008?, p.3), como se tratasse de uma ação corriqueira, destituída de afeição e de emoção, característica das relações que na sociedade burguesa são perpassadas pela frieza e pelo princípio da troca. Sobre essa questão, as reflexões de Adorno (1993, p.35) são relevantes. Assim, ele diz: “Dentro dessa empresa tão organizada já não há mais lugar para a emoção humana, a doação está necessariamente vinculada à humilhação pelo ato de repartir, de avaliar exatamente, em suma, pelo fato de tratar como objeto aquele que é presenteado".

Sobre o caminho percorrido pela Chapeuzinho, na versão de Perrault (2012), relata-se que ela "seguiu pelo caminho mais longo, entretendo-se em catar castanhas, correr atrás das borboletas e fazer buquês com as flores que encontrava" (PERRAULT, 2012, p.7-8). Assim, podese imaginar a relação da menina com a natureza e, nessa relação, a presença do belo, da felicidade, do tempo para além do tempo do relógio, do tempo cronometrado.

No momento que Chapeuzinho encontra o lobo na casa da avó, Perrault (2012, p.10) descreve: "Chapeuzinho Vermelho tirou a roupa e foi se enfiar na cama". Já na segunda versão analisada, "o lobo pediu para ela chegar mais perto" (MARQUES, 2008?, p.9). O lobo apenas pede que a menina se aproxime, não há menção ao deitar, ou tirar a roupa. Na versão de Perrault (2012, p.11), "o lobo malvado se jogou em cima de Chapeuzinho Vermelho e a comeu" e na versão de Marques (2008?, p.11) “Então o lobo pulou da cama e correu para pegar Chapeuzinho".

Na versão de Marques (2008?, p.9-10), narra-se:

- Vovó, que orelhas grandes!, disse Chapeuzinho.

- É para te ouvir melhor, disse o lobo.

- Que olhos enormes, vovó! 
- É pra te ver melhor!

- Que nariz comprido!

- É para te cheirar!

- E essa boca, vovozinha? Que grande!

- É para te devorar!

São aspectos voltados ao olfato, à audição e ao paladar, ou seja, aos sentidos. Na versão de Perrault (2012, p.10-11), essa passagem indica que a violência pode vir de outros meios.

Minha avó, que braços grandes você tem!

É para abraçar você melhor, minha neta.

Minha avó, que pernas grandes você tem!

É para correr melhor, minha filha.

Minha avó, que orelhas grandes você tem!

É para escutar melhor, minha filha.

Minha avó, que olhos grandes você tem!

É para enxergar você melhor, minha filha.

Minha avó, que dentes grandes você tem!

É para comer você.

A narração de Perrault remete a Benjamin (2018), quando se refere à narração como ensinamento compartilhado entre gerações. De acordo com Benjamin (2018), as melhores histórias escritas são as que mais preservam os aspectos da narrativa oral. O que é narrado tem por objetivo ensinar algo. O que é possível perceber nas linhas e entrelinhas da versão de Perrault (2012) e evidencia-se na moral da história. Ao expressar

Vemos aqui as meninas,

E sobretudo as mocinhas

Lindas, elegantes e finas,

Não devem a qualquer um escutar.

Falo 'do' lobo, pois nem todo eles

São de fato equiparáveis.

Alguns são até muito amáveis,

Serenos, sem fel nem irritação.

Esses doces lobos, com toda educação,

Acompanham as jovens senhoritas

Pelos becos afora e além do portão.

Mas ai! Esses lobos gentis e prestimosos,

São, entre todos, os mais perigosos (PERRAULT, 2012, p.11).

Como as histórias tinham um cunho moral, há a abertura para se pensar que o lobo pode

Periódico Horizontes - USF - Itatiba, SP - Brasil - e021066 
ser um animal, mas também uma pessoa próxima de quem, inicialmente, não há desconfiança. Tanto que ao encontrar "o compadre lobo" (PERRAULT, 2012, p.6), a Chapeuzinho não demonstrou ter medo dele. Essa proximidade não é revelada na história de Marques (2008?, p.5), na qual simplesmente se diz que "a menina encontrou o lobo".

A versão de Marques [2008?] não apresenta uma moral e nem um ensinamento nas suas entrelinhas; apresenta-se um final feliz, repetindo o sempre-igual, uma marca da indústria cultural: "Chapeuzinho apareceu e disse que o lobo havia engolido a vovó. O caçador abriu a barriga do lobo e tirou a vovó sã e salva" (MARQUES, 2008?, p.13).

A narrativa, segundo Benjamin (2018), tem uma intencionalidade prática, por isso, tem um aconselhamento, uma aprendizagem importante para a vida. O ensino por meio dela é, conforme Benjamin (2018), o compartilhamento da experiência, mas o narrador não apresenta todas as conclusões e as respostas, ou seja, pelas entrelinhas e dicas, vai conduzindo o ouvinte ou o leitor à compreensão da sua mensagem, indicando que "conselho, entretecido na matéria da vida vivida, é sabedoria" (BENJAMIN, 2018, p.25). Nesse sentido, podemos pensar que a versão de Marques [2008?] exprime o que Benjamin (2018) define como falência da habilidade de dar conselhos. Em meio às mudanças produtivas e históricas, as relações entre as pessoas foram modificadas e, com elas, alterada a potencialidade de socializar experiências, diz Benjamin (2018).

Na versão de Perrault (2012), os acontecimentos da narrativa estão interligados, desde a descrição de como a menina ficou conhecida como Chapeuzinho Vermelho à sua beleza e à sua ingenuidade de não perceber as intenções do lobo mau. A conexão entre os fatos contribui para os leitores manterem a atenção e se abrirem para novas experiências. Observamos, ainda, a preocupação do autor com a comunicação, explicitada pela utilização de um amplo vocabulário com palavras capazes de descrever os acontecimentos e os cenários da história com riqueza de detalhes, transportando o leitor para o interior da história, de modo a viver, a ressignificar cada acontecimento e a torná-lo parte de sua experiência.

A boa avó, que estava de cama por andar adoentada, gritou: 'Puxe a lingueta e o ferrolho se abrirá.' O lobo puxou a lingueta e a porta se abriu. Jogou-se sobre a boa mulher e a devorou num piscar de olhos, pois fazia três dias que não comia. Depois fechou a porta e foi se deitar na cama da avó, à espera de Chapeuzinho Vermelho, que pouco tempo depois bateu à porta. Toc, toc, toc. (PERRAULT, 2012, p.16). 
Com essa passagem, evidenciamos que, embora essa narrativa apresenta uma lição de moral - "Vemos aqui que as meninas, e sobretudo as mocinhas lindas, elegantes e finas, não devem a qualquer um escutar" (PERRAULT, 2012, p.40) -, ela denuncia o quão bárbaros os homens podem ser. Por meio da fantasia, o autor evidencia situações de abuso sexual que eram recorrentes naquele período, por exemplo, ao dizer: "Esses lobos gentis e prestimosos, são, entre todos, os mais perigosos" (PERRAULT, 2012, p.40). Mais que um entretenimento, essa literatura propõe reflexões às crianças, leva-as a pensarem e a compreenderem parte da história, inclusive da constituição da própria infância. Pelo exposto, compreendemos que a preocupação do autor é compartilhar suas experiências, levando-nos a pensar no que Benjamin (1987) descreve como a arte de "comunicar", de compartilhar o que viveu, o que imaginou e o que experienciou.

Já na versão adaptada por Marques [2008?] notamos mudança no enredo da história, desde a utilização de um vocabulário simples à desconexão entre os acontecimentos e à falta de detalhes, seja pela dificuldade em narrar ou pelo interesse em adequar a história aos anseios mercadológicos, reduzindo o texto e apresentando muitas imagens que falam por si; assim, elimina a possibilidade de o leitor imaginar para além das representações que lhe são dadas. $A$ simplificação da linguagem, a ausência de elementos que poderiam transmitir aos leitores experiências de outros tempos, como a visão de infância em outro momento histórico, resulta em uma literatura infantil simplificada, adaptada conforme os preceitos do mercado literário. Isso posto, compreendemos que a literatura infantil deixa de possibilitar o desenvolvimento da imaginação, da criatividade, aspectos apontados por Abramovich (1997) como fundamentais para que as crianças descubram e compreendam o mundo. Nesses termos, a literatura infantil que se limita à mercadoria inviabiliza o acesso aos bens culturais e pode culminar no que Adorno (1970) denomina de adesão cega ocasionada pela manipulação da indústria cultural, que busca desenvolver nos indivíduos, desde a infância, atitudes, valores e interesses padronizados.

\section{Considerações finais}

Ao analisarmos as duas versões da história Chapeuzinho Vermelho, compreendemos que, ao permitir a relação entre o passado e o presente, a literatura viabiliza o que Benjamin (1987) 
chamou de experiência, o conhecimento construído a partir do contato com a cultura, com a tradição. Mediante a reflexão de Benjamin (1987), entendemos que Perrault (2012), ao recontar histórias narradas pelos camponeses, realiza o movimento entre passado e presente, trazendo mais do que o simples conselho aos leitores, pois se trata de compartilhar a experiência constituída por ele como escritor e como ouvinte, bem como as experiências daqueles que contavam as histórias.

A versão da história de Perrault (2012) tem indícios da narração que Benjamin defende. Uma narração que ensina, que contempla o contexto histórico e social, que compartilha conselhos para a vida, os quais são ressignificados e se transformam em experiências daqueles que os ouvem. Observamos a preocupação de Perrault (2012) em narrar os fatos de modo que nenhum deles deixe de ser percebido pelo leitor e, ao mesmo tempo, não são apresentados como meras descrições da realidade. Nessa versão, encontramos a preocupação com as crianças, cuja consolidação veio com a sociedade burguesa. Ela apresenta uma moral, conservando a experiência constituída por Perrault, ao ouvir as histórias contadas pelos camponeses e expressando uma intencionalidade. Sobre esse tema, Benjamin (1987) destaca que se trata da transmissão de um conselho do narrador aos ouvintes.

Com essas reflexões acerca da literatura infantil, não queremos eliminar a literatura infantil do processo educacional, mas chamar a atenção para o fato de que, com o desenvolvimento da sociedade e das tecnologias, foram aprimorados os meios, porém o conteúdo vai se perdendo. Nem mesmo a literatura infantil escapa à indústria cultural, cujo objetivo é apresentar a novidade, mas esta novidade é a repetição e não a possibilidade de ampliação do pensamento.

A análise das duas versões da história Chapeuzinho Vermelho nos permite dizer que o processo que viabilizou o acesso à literatura infantil para as diferentes classes sociais é o mesmo que impôs limite aos conteúdos presentes nesses livros. As formas de controle recaem sobre o conteúdo do pensamento e da imaginação, à medida que apresenta o fato, sem dar elementos para imaginá-lo. Conforme Adorno (1993), uma linguagem mais elaborada busca a compreensão do conceito, ao contrário de uma linguagem vazia, mediante a qual os homens são direcionados ao fato em si.

Nesses termos concordamos com Benjamin (1987), quando diz que a crise na capacidade 
de narrar culmina na crise da transmissão de conhecimento. Essa crise tem seu início com o desenvolvimento tecnológico, acirrando-se com o desenvolvimento da imprensa. Portanto, tais apontamentos são no sentido de trazer inquietações para que possamos pensar em caminhos para a superação da crise que alcança também as práticas pedagógicas com os clássicos da literatura infantil. É relevante percebermos a presença da indústria cultural nas histórias que contamos, bem como a importância da literatura infantil como instrumento para a compreensão do passado e sua trajetória histórica, para a percepção de que o presente não é a única forma de existência; ele pode ser diferente do que é.

\section{Referências}

ABRAMOVICH, F. Literatura infantil: gostosuras e bobices. São Paulo: Scipione, 1997.

ADORNO, T. W. Educação e emancipação. Trad. Wolfgang Leo Maar. Rio de Janeiro: Paz e Terra, 1970.

ADORNO, T. W. Mínima moralia. São Paulo: Ática, 1993.

ADORNO, T. W. Teoria da semicultura. Revista Educação e Sociedade, n.56, ano XVII, p.388-411, dez. 1996.

ADORNO, T. W.; HORKHEIMER, M. Dialética do esclarecimento: fundamentos filosóficos. Rio de Janeiro: Zahar, 1985.

ARIES, P. História social da criança e da família. Trad. Dora Flasksman. 2. ed. Rio de Janeiro: Livros Técnicos e Científicos. 1981.

BENJAMIN, W. Experiência e pobreza. In: BENJAMIN, W. Magia e técnica, arte e política: ensaios sobre literatura e história da cultura (Obras Escolhidas, vol.1). Trad. Sérgio Paulo Rouanet. São Paulo, Brasiliense, 1987. p.197-221.

BENJAMIN, W. Reflexões sobre a criança, o brinquedo e a educação. Trad. Marcus Vinicius Mazzari. 34. Ed., São Paulo: Duas Cidades, 2002.

BENJAMIN, W. O contador de histórias: considerações sobre a obra de Nikolai Leskov. In: BENJAMIN, W. A arte de contar histórias. Trad. Georg Otte, Marcelo Backes e Patrícia Lavelle. São Paulo: Hedra, 2018. (Coleção Walter Benjamin).

CALVINO, I. Por que ler os clássicos. Trad. Nilson Moulin. São Paulo: Companhia das Letras, 1993. 
COELHO, N. N. Panorama histórico da literatura infantil-juvenil: das origens indoeuropéias ao Brasil contemporâneo. 3. ed. ref. e ampl. São Paulo: Quíron, 1985.

COSTA, S. S; FONTANA, R. L. M; RODRIGUES, A. J.; SILVA, J. A. B. Teorias demográficas e o crescimento populacional no mundo. Ciências Humanas e Sociais Unit, Aracaju, v.2, n.3, p.113124, mar. 2015. Disponível em:

https://periodicos.set.edu.br/index.php/cadernohumanas/article/view/1951/1209. Acesso em: 23 jul. 2020.

GIOVINAZZO JÚNIOR, C. A. Cultura, educação e indústria cultural: a pedagogização das práticas culturais e as transformações da literatura infantil. In: COLÓQUIO INTERNACIONAL TEORIA CRÍTICA E EDUCAÇÃO, 2004, Araraquara. Anais [...].Araraquara: UNIMED, 2004, p.644-649.

KRAMER, S. Infância, cultura contemporânea e educação contra a barbárie. Revista Teias. v.1, n.2, p.1-14. 2000. Disponível em: https://www.e-

publicacoes.uerj.br/index.php/revistateias/article/view/23857. Acesso em: 04 maio 2020.

MARCUSE, H. Ideologia da sociedade industrial: o homem unidimensional. Trad. Giasone Rebuá. Rio de Janeiro: Zahar, 1973.

MARCUSE, H. Ecologia e crítica da sociedade moderna. Dissonância, Campinas, v.2, n.1-2 (Dossiê Herbert Marcuse), p.190-203, jun.2018. Disponível em:

file://C:/Users/mtbga/Downloads/208-85-PB.pdf. Acesso em: 20 nov. 2021.

MARQUES, C. Chapeuzinho Vermelho. Blumenau: Todolivro, [2008?].

MARX, K; ENGELS, F. Textos sobre educação e ensino. Campinas: Navegando, 2011.

OLIVEIRA, M. R. F. A razão instrumental e os processos semiformativos dos indivíduos:

implicações no trabalho docente voltado a primeira infância. In: GASPARIN, J. L. MASHIBA, G. C. X. (orgs,). Os clássicos e a educação: um retorno necessário em tempos de crise. Curitiba: CRV, 2019, p.115-127.

OLIVEIRA, M. R. F.; GALUCH, M. T. B.; GIOVINAZZO JÚNIOR, C. A. Indústria cultural e semiformação: democracia e educação sob ataque nos países ibero-americanos à luz da teoria crítica. Revista Ibero-Americana de Estudos em Educação, Araraquara, v.14, n.esp.4, p.18831898, dez. 2019.

PERRAULT, C. Um conto de fadas Chapeuzinho Vermelho. Trad. Maria Luiza X. de A. Borges. Rio de Janeiro: Zahar, 2012.

SAVIANI, D. Pedagogia histórico-crítica: primeiras aproximações. 11. ed. Campinas: Autores Associados, 2013. 
Recebido em julho 2021.

Aprovado em novembro 2021. 